\title{
The Influence of Tool Geometry towards Cutting Performance in Machining Aluminium 7075
}

\author{
Jumali Muhammad Syafik ${ }^{1, *}$, Muhamad Mohd Razali ${ }^{2}$, and Sundi Syahrul Azwan ${ }^{1}$ \\ ${ }^{1}$ Faculty of Engineering Technology, Universiti Teknikal Malaysia Melaka, Malaysia \\ ${ }^{2}$ Faculty of Manufacturing Engineering, Universiti Teknikal Malaysia Melaka, Malaysia
}

\begin{abstract}
Aerospace industries often use Computer Numerical Control (CNC) machining in manufacturing aerospace parts. Aluminium 7075 is the most common material used as aircraft components. This research aims to produce end mill with optimum geometry in terms of the helix angle, primary radial relief angle and secondary relief angle. End mills with different geometry parameters are tested on Aluminium 7075 and data on surface roughness and tool wear were collected. The results were then analysed to determine which parameters brought the optimum result with regards to surface roughness and tool wear.
\end{abstract}

\section{Introduction}

Machining is the most common material removal process being practiced in the metal fabrication industry such as in the aerospace and automotive industries. This is due to the flexible nature of machining in that it can be used to produce almost any design features of metal components. The capability of machining is hugely improved through the introduction of advanced technologies such as Computer Numerical Control (CNC) and Computer-Aided Manufacturing (CAM).

In aerospace industry where volume is low and flexibility is high, machining is one the most profitable and viable method of production. Conventional machining method using $\mathrm{CNC}$ machines is often used to produce aerospace parts. Variable parameters in machining are spindle speed, feed rate and depth of cut. These three parameters partly determine whether any parts that are produced have good surface finish while improving cutting tool performance and having longer tool life during machining. However, in modern CAM software, higher cutting speed is obtained by manipulating different cutting strategies in order to fully utilize the capabilities of CNC machines.

In order to investigate the relationship between cutting speed with surface finish and tool wear, a combination of varied primary and secondary clearance angles and also the flute helix angle of end mill will be used to determine the optimum tool geometry to cut Aluminium 7075. Aluminium 7075 is commonly used for aircraft structures because it has high strength and also the best machinability among Aluminium Alloys. Many researchers studied the effects of helix angle to vibrations. Omar et al. (2007) found that cutting forces

*Corresponding author: syafik@utem.edu.my 
decrease as helix angle increases. Zatarain et al. (2006) found that helix angle reduces the importance of higher order harmonics vibrations. The effect of helix angle on surface roughness is studied by Buj-Corral et. al (2011) who pointed out that for helix angles other than zero, the same roughness pattern appears on the workpiece's surface along each helix pitch regardless of helix angle. However the research was done by cutting steel. Vobrouček (2015) suggested for changing surface quality, friction and toughness of mill, we must change the clearance angle on the tool; the research was done by cutting Akrylonitrilbutadienstyrene (ABS) plastic. Figure 1 shows end mill nomenclature.

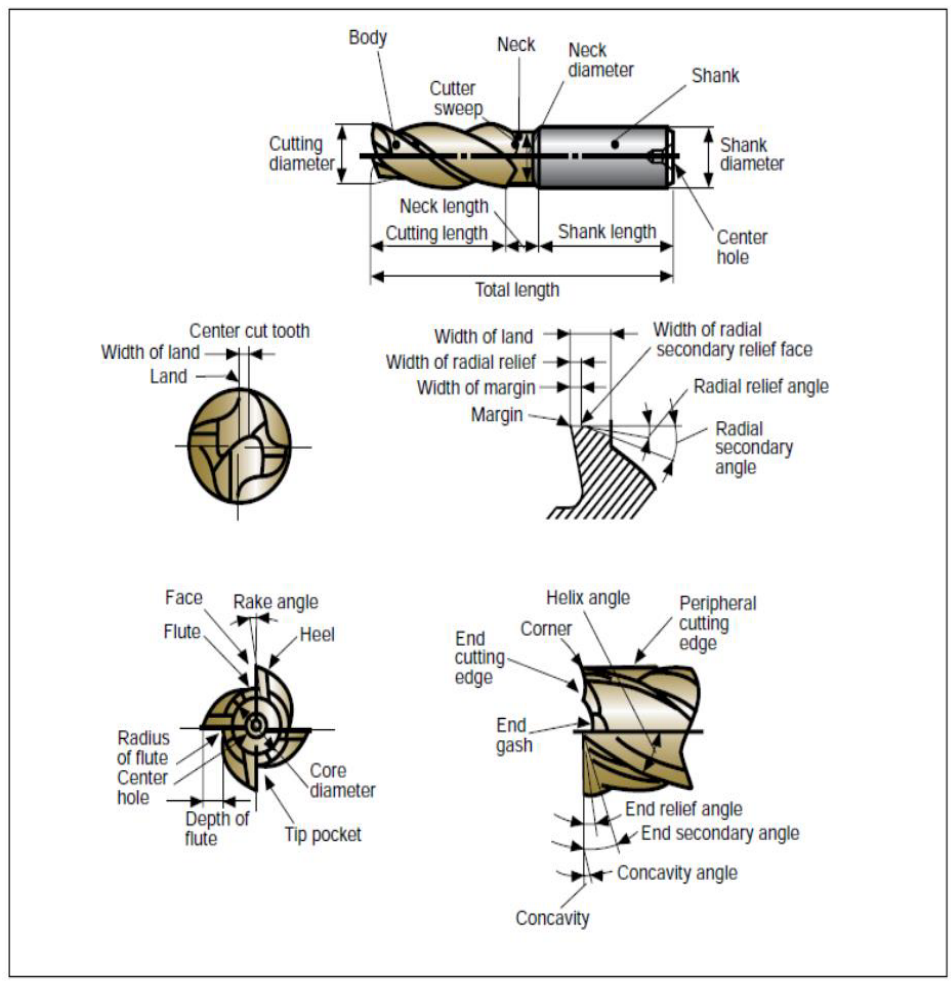

Fig. 1. End mill Nomenclature

\section{Experimental setup}

Three critical parameters are considered in the fabrication of the end mills. The parameters are helix angle $\left(30^{\circ}-60^{\circ}\right)$, primary relief angle $\left(5^{\circ}-9^{\circ}\right)$ and secondary radial relief angle $\left(14^{\circ}-\right.$ $17^{\circ}$ ). The helix angle of $30^{\circ}-60^{\circ}$ is selected because these are the angles typically found in the market and recommended by tool manufacturers. The primary and secondary relief angles are also angles recommended by tool manufacturers that are commonly used in end mill manufacturing.

These angles were used in Design of Experiment (DOE) using Full Factorial method to generate the matrix for experimental specimens. The matrix is generated using Minitab 16 software. The software was also used later on to analyse the results after all experiments are completed. Based on the Full Factorial method, there are eight specimens of end mill produced. One replication was added which makes the total number of specimens 16 pieces. Table 1 shows the matrix of parameters that are used in producing the end mill. 
Table 1. Experimental setup

\begin{tabular}{|c|c|c|c|}
\hline Run & $\begin{array}{c}\text { A:Helix Angle } \\
\text { [Degree] }\end{array}$ & $\begin{array}{c}\text { B:Primary Relief Angle } \\
\text { [Degree] }\end{array}$ & $\begin{array}{c}\text { C:Secondary Relief } \\
\text { Angle [Degree] }\end{array}$ \\
\hline $\mathbf{1}$ & 60 & 9 & 14 \\
\hline $\mathbf{2}$ & 30 & 5 & 17 \\
\hline $\mathbf{3}$ & 60 & 5 & 17 \\
\hline $\mathbf{4}$ & 60 & 9 & 17 \\
\hline $\mathbf{5}$ & 30 & 5 & 14 \\
\hline $\mathbf{6}$ & 60 & 9 & 14 \\
\hline $\mathbf{7}$ & 30 & 9 & 17 \\
\hline $\mathbf{8}$ & 60 & 5 & 14 \\
\hline $\mathbf{9}$ & 60 & 5 & 14 \\
\hline $\mathbf{1 0}$ & 60 & 9 & 17 \\
\hline $\mathbf{1 1}$ & 30 & 9 & 14 \\
\hline $\mathbf{1 2}$ & 30 & 9 & 17 \\
\hline $\mathbf{1 3}$ & 30 & 9 & 14 \\
\hline $\mathbf{1 4}$ & 30 & 5 & 17 \\
\hline $\mathbf{1 5}$ & 60 & 5 & 17 \\
\hline $\mathbf{1 6}$ & 30 & 5 & 14 \\
\hline
\end{tabular}

\section{Experimental results and analysis}

The following results were obtained after machining.

Table 2. Experimental results

\begin{tabular}{|c|c|c|c|c|c|c|}
\hline Run & $\begin{array}{c}\text { A:Helix } \\
\text { angle } \\
{[\text { Degree] }}\end{array}$ & $\begin{array}{c}\text { B:Primary } \\
\text { Relieve } \\
\text { Angle } \\
{[\text { Degree] }}\end{array}$ & $\begin{array}{c}\text { C:Secondary } \\
\text { Relieve Angle } \\
{[\text { Degree] }}\end{array}$ & $\begin{array}{c}\text { Axial } \\
\text { Surface } \\
\text { Roughness } \\
{[\boldsymbol{\mu m}]}\end{array}$ & $\begin{array}{c}\text { Radial } \\
\text { Surface } \\
\text { Roughness } \\
{[\boldsymbol{\mu} \mathbf{m}]}\end{array}$ & $\begin{array}{c}\text { Tool } \\
\text { Wear } \\
{[\boldsymbol{\mu} \mathbf{m}]}\end{array}$ \\
\hline $\mathbf{1}$ & 60 & 9 & 14 & 0.48 & 0.38 & 83.9 \\
\hline $\mathbf{2}$ & 30 & 5 & 17 & 0.24 & 0.32 & 78.54 \\
\hline $\mathbf{3}$ & 60 & 5 & 17 & 0.29 & 0.44 & 89.46 \\
\hline $\mathbf{4}$ & 60 & 9 & 17 & 0.58 & 0.57 & 114.83 \\
\hline $\mathbf{5}$ & 30 & 5 & 14 & 0.37 & 0.24 & 84.34 \\
\hline $\mathbf{6}$ & 60 & 9 & 14 & 0.67 & 0.5 & 194.06 \\
\hline $\mathbf{7}$ & 30 & 9 & 17 & 0.26 & 0.45 & 59.84 \\
\hline $\mathbf{8}$ & 60 & 5 & 14 & 0.47 & 0.58 & 49.39 \\
\hline $\mathbf{9}$ & 60 & 5 & 14 & 0.38 & 0.43 & 43.64 \\
\hline $\mathbf{1 0}$ & 60 & 9 & 17 & 0.49 & 0.34 & 101.93 \\
\hline $\mathbf{1 1}$ & 30 & 9 & 14 & 0.31 & 0.26 & 64.05 \\
\hline $\mathbf{1 2}$ & 30 & 9 & 17 & 0.33 & 0.35 & 69.55 \\
\hline $\mathbf{1 3}$ & 30 & 9 & 14 & 0.37 & 0.33 & 60.42 \\
\hline $\mathbf{1 4}$ & 30 & 5 & 17 & 0.38 & 0.4 & 82.91 \\
\hline $\mathbf{1 5}$ & 60 & 5 & 17 & 0.46 & 0.51 & 75.92 \\
\hline $\mathbf{1 6}$ & 30 & 5 & 14 & 0.37 & 0.32 & 76.29 \\
\hline
\end{tabular}




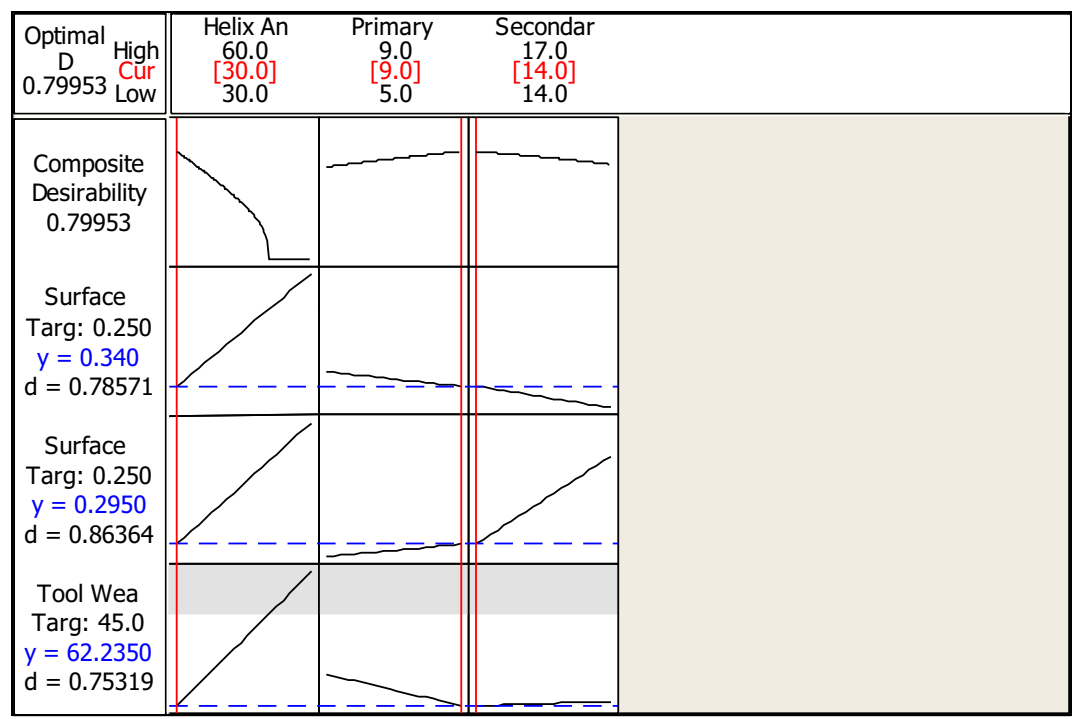

Fig. 2. Response Optimization Graph

Figure 2 shows response optimization graph. Response optimization is an analysis done to get the optimum values for the combination of all parameters. This analysis will provide the prediction of which combination angles will provide the best trade-off between axial and radial surface roughness and also tool wear. From this graph, it can be seen that the recommended values are as follows;

a) Helix Angle: $30^{\circ}$

b) Primary Radial Relief Angle: $9^{\circ}$

c) Secondary Relief Angle: $14^{\circ}$

By using this combination of angles, based on software calculation, the response will be as follows;

a) Axial Surface Roughness: $0.340 \mu \mathrm{m}$

b) Radial Surface Roughness: $0.295 \mu \mathrm{m}$

c) Tool wear: $62.2350 \mu \mathrm{m}$

\section{Conclusion}

From the results and analysis done the following conclusions can be deduced:

a) Higher primary radial relief angle gives higher tool wear. Higher secondary radial relief angle gives lower tool wear.

b) Higher helix angle gives higher tool wear.

c) Higher primary radial relief angle gives higher axial surface roughness but lower radial surface roughness. Higher secondary radial relief angle gives lower tool wear and vice versa.

The author would like to acknowledge the Ministry of Science, Technology and Innovation and Universiti Teknikal Malaysia Melaka for the support and funding throughout this study. 


\section{References}

1. M. Alauddin, M.A El Baradie, M.S.J Hashmi, J. Mater. Process Tech., 71, 456 (1997)

2. D. Begic Hajdarevic, A. Cekic A, M Kulenovic, Procedia Engineering, 69, 291 (2014)

3. I. Buj Corral, J. Vivancos Calvet, H. Gonzalez Rojas, Int. J. Mach. Tool Manu., 51, 889 (2011)

4. T. Dursun, C. Soutis, Materials \& Design, 56, 862 (2014)

5. J.A. Ghani, C.H. Che Haron, S.H. Hamdan, A.Y.M. Said, S.H. Tomadi, 39, 4449 (2013)

6. ISO 4287, Geometrical Product Specifications (GPS) -Surface texture: Profile methodTerms, definitions and surface texture parameters, (1997)

7. ISO 8688-2, Tool Life Testing In Milling - Part 2: End Milling, (1989)

8. S. Kalidas, P. Palanisamy, J. Adv. Manu. Sys., 13, 1 (2014)

9. S.M. Lou, C.J. Chen, M.C. Li, J. Ind. Tech., 5, 1 (1999)

10. D.C. Montgomery, Design and Analysis of Experiments, (John Wiley \& sons, Inc, Hoboken, 2005)

11. O.E.E.K. Omar, T. El Wardany, E. Ng, M.A. Elbestawi, Int. J. Mach. Tool. Manu., 47, 1263 (2007)

12. J. Vobroucek, Procedia Engineering, 100, 1556 (2015)

13. M. Zatarain, J. Munoa, G. Peigne, T. Insperger, (2006), CIRP Annals of Manu. Tech., 55, 365 (2006) 